\title{
The Maturity Evaluation and Comparison of Robots Science Popular Education between Fujian and Taiwan
}

\author{
Mei Chiao Lai \\ Department of Logistics Management \\ Fujian and Taiwan Industrial Collaboration and Management Innovation Research Center \\ Fuzhou University of International Studies and Trade \\ Fuzhou, China 350202
}

\author{
Xiulian $\mathrm{Hu}$ \\ Department of Logistics Management \\ Fuzhou University of International Studies and Trade \\ Fuzhou, China 350202
}

\author{
Wu Der Tsay \\ Research \& Development Center \\ Fujian and Taiwan Industrial Collaboration and \\ Management Innovation Research Center \\ Fuzhou University of International Studies and Trade \\ Fuzhou, China 350202
}

\begin{abstract}
This paper applied the International Standard Maturity Criterion to self-assess the maturity of the quality of robots science popular education and compared its differences cross-strait. The research method used was experts' and scholars' questionnaire survey. Five assessment dimensions of ISO9004 guideline including popular science education system, management responsibility, resource management, service implementation and measurement, analysis and improvement were used to design the questionnaire. Data were collected from the experts and scholars from cross-strait. The study found that the total maturity of five dimensions of robots science popular education in Fujian fell between grade 3 (with a formal stable system plan) to grade 4 (continuing continuous improvement), and the total maturity of Taiwan fell to 3 points. Based on this, the study will provide government agencies, academics, and industry with suggestions for them to improve the policies and methods when they offer the robots science popular education.
\end{abstract}

Keywords-robots science popular education; international standards of maturity; self-assess

\section{INTRODUCTION}

General Secretary $\mathrm{Hu}$ Jintao pointed out on March 5, 2011: "China's promotion of scientific development and accelerated transformation of economic development depends essentially on science and technology, and the basis is education. The key is talent." (March 5, 2011 Tencent News). Premier Li Keqiang served as a promoter of the "Made in China 2025" program, developing smart factories, robots and automation, and was promoted by more than 20 ministries and commissions such as the Ministry of Industry and Information Technology, the National Development and Reform Commission, the Ministry of Science and
Technology, and the Ministry of Education. Under the speed of innovation and technology development of the Intelligent Robots and Automation Industry 4.0, robots science popular education is the new future spindle based on the industry. "Machine Substitution" is the automation of the production process. Robots science education reforms have been proposed one after another. Its main purpose is to promote the popularization of robots education systems

In 2013, the Ministry of Education of the People's Republic of China issued a document to formally incorporate robot quality education into one of the eight major sports leagues of the country's schools and incorporate it into education and teaching courses. This is a milestone in robot education. On December 5, 2015, the first Robot Sports Competition hosted by Heilongjiang Provincial Party Committee Propaganda Department, Heilongjiang Provincial Sports Bureau, Heilongjiang Robot Association and other departments was held in Harbin. The robot movement was first included in the Heilongjiang Provincial Fitness Campaign. In 2016, Heilongjiang will increase the popularization of robot education and training, further promote the construction of robot education and teaching activities, and build Heilongjiang Province into a demonstration province of robot quality education in China. Robot education is in full swing around the world.

The robot science education system has started in Taiwan. Many schools have established elective courses in robot education and formed a certain amount of teachers. Since Tamkang University established the first robotics research institute in Taiwan in 2007, not only National Taiwan University, National Tsinghua University, National Chiao Tung University, and National Cheng Kung University have established research centers related to robots, including Tai 
Keda, Nantai University of Science and Technology, Taipei City University of Science and Technology and Kaohsiung. Technical schools such as First Science and Technology University have also been successively added. According to the "Ministry of Education" University College Curriculum Information Network, robots are used as the key word in the 2013 semester of the academic year, and 29 institutions and 51 institutions in Taiwan can be searched for a total of 127 courses. Chen Xiangwei, a counselor at the Taipei Science and Education Museum responsible for coursework, said that robotics courses are entertaining and educational and have been popular for many years. This is also a great opportunity for the development of robots education. However, the quality of education and the effectiveness of its promotion are a topic worthy of discussion. Therefore, the purpose of this plan is to take the ISO9004 guideline to self-assess the maturity of the quality of robot science popular education cross Taiwan Strait.

\section{LITERATURE REVIEW}

\section{A. Robot Science Popular Education}

In science and technology, scientists will give a clear definition of every technical term, but the definition of robot has not been unified so far. One of the reasons is that robots are still developing. The fundamental reason is that robots involve the concept of human beings, making them difficult to answer philosophical questions. The definition of robotics by our country's scientists is: "The robot is an automated machine. The difference is that this kind of machine has some intelligence capabilities similar to humans or biology, such as perception ability, planning ability, action ability, and coordination ability. Highly collaborative automated machine (Sougou Wiki). The educational value of the robot makes it possible to use it as a home educational toy, as a vehicle for extracurricular activities in schools, and as a carrier for basic education courses3. At the same time, the robot as a platform enables students to comprehensively and comprehensively understand the advanced technologies of modern industrial design, machinery, electronics, sensors, computer software, hardware, human-computer interaction, artificial intelligence and many other fields, and personally contact and experience modern technologies. High-tech, stimulating students' awareness of innovation and the potential to create inventions while acquiring students' scientific knowledge and practical ability.

\section{B. Self-assessment Maturity}

Maturity is a new type of evaluation method. It has been widely used in the field of management. The idea of maturity stems primarily from quality management practices that have a history of more than 60 years. According to the maturity assessment model and guidelines in the ISO9004 international standard guideline, maturity assessment is divided into five dimensions, they are institutional systems, management responsibilities, resource management, service realization, measurement, analysis, and improvement, see "Table I". The evaluation results of robotic science education maturity are divided into five levels, ranging from the worst to the best. The worst level is 1 point (no formal scheme), followed by 2 points (reactive scheme), and 3 points (formally the stable system plan) is again 4 points (continuing continuous improvement) and the best grade is 5 points (to achieve optimal operation).

TABLE I. FIVE DIMENSIONS OF ISO9004 INTERNATIONAL STANDARD MATURITY EVALUATION SYSTEM

\begin{tabular}{|l|l|}
\hline \multicolumn{1}{|c|}{$\begin{array}{c}\text { Five Dimensions of the } \\
\text { system }\end{array}$} & \multicolumn{1}{c|}{ Implementation details } \\
\hline D1:Institutional Systems & $\begin{array}{l}\text { (1) Policies, Regulations and Systems } \\
\text { (2) System Assurance Management } \\
\text { System }\end{array}$ \\
\hline $\begin{array}{l}\text { D2:Management } \\
\text { Responsibilities }\end{array}$ & $\begin{array}{l}\text { (1) Planning Commitment Policy } \\
\text { (2) System Management } \\
\text { (3) Responsibility, authority } \\
\text { (4) Communication }\end{array}$ \\
\hline D3:Resource Management & $\begin{array}{l}\text { (1) Resource supply } \\
\text { (2) human resources }\end{array}$ \\
& $\begin{array}{l}\text { (3)infrastructure } \\
\text { (4) work environment }\end{array}$ \\
\hline D4:Service Realization & $\begin{array}{l}\text { (1) Service realization planning. } \\
\text { (2) Design-related process } \\
\text { (3) Service Operation } \\
\text { (4) Measurement and Control } \\
\text { Monitoring Instruments }\end{array}$ \\
\hline Analysis, & $\begin{array}{l}\text { (1) Measurement and monitoring } \\
\text { (2) Do not meet service control } \\
\text { (3) Data analysis } \\
\text { (4) Improvement }\end{array}$ \\
\hline
\end{tabular}

\section{RESEARCH METHOD}

The evaluation and comparison of robotic science popular education systems across the Taiwan Strait, it is divided into five steps. Firstly, a robotic science popular education maturity questionnaire is designed based on the contents of the five criteria and 18 questions of the maturity assessment system; secondly, to invite experts and scholars to analyze the designed questionnaires for surface validity, content validity, and construct validity, and then modify the contents of the questionnaire according to experts' opinions, and then make 20 predictions. The reliability and validity of the measurement questionnaires are measured. After the untrustworthy item eliminated, the questionnaire is fixed; thirdly, the assessment of maturity is based on the questionnaire survey. The assessors are scientific experts and scholars of robots across Taiwan Straits. The main purpose is to understand the maturity of robot science popular education of Fujian and Taiwan through surveys, fourthly, calculate the total scores and averages of the five dimensions of maturity assessment of cross-strait science popular education. Compare the maturity level of science popular education with the maturity level of ISO9004, and analyze the differences.

\section{RESEARCH RESULTS}

The maturity of robotic science popular education in Fujian Province evaluated the results of D1, D2, D3, D4, and D5 according to the five criteria of the ISO9004 system. The scores were $3.5,4.0,3.75,3$, and 2 respectively (see table 3 below). The highest level of D2 management responsibility falls on the fourth level, indicating that the organization is 
well-organized from the central government to the local government; the D1 system falls on the third level; the program that officially implements laws and regulations; and the fourth level emphasizes continuous improvement and upgrading; and the D3 resource management falls on the third level, with the self-raising of departments and social sponsorship, and the marked improvement in the scientific quality of the fourth-class citizens; D4 services have fallen into third level; D5 measurement, analysis, and improvement have fallen to the second level. Only the supervision of the National Association of Popular Science has not yet statistical data integration phase. The overall maturity is 3.25 points, and it belongs to grades 3 to 4 .

The five criteria D1, D2, D3, D4, and D5 in Taiwan selfassessment results are $3,2,3.25,3.75$, and 3 respectively (see Table 3 below). The D1 system has a program that officially implements regulations that fall into three levels; D2 Responsibility for management falls on level 2 where there is a dedicated organization but there is no systematic and responsible implementation unit; D3 resources management falls between level 3 and level 4; through selfraising by departments and social sponsorship, the quality of citizenship is significantly improved; D4 services realization, the type of activity is quite abundant, and some positive effects are received between Level 3 and Level 4; D5 measurement, analysis and improvement fall at the third level, with statistical data integration stage. The overall maturity of robot science education in Taiwan is 3.00 points, indicating that robot science popular education has a formal stable system program. The maturity levels and radar chart of robot science popular education between Fujian and Taiwan are shown in the "Table II" and "Fig. 1".

TABLE II. COMPARISON OF Robot POPULAR SCIENCE EdUCATION MATURITY BETWEEN FUJIAN AND TAIWAN

\begin{tabular}{|c|c|c|c|c|c|c|}
\hline \multirow{2}{*}{ Five Dimensions } & \multirow{2}{*}{ Evaluation item } & \multicolumn{2}{|c|}{ Item ave. } & \multicolumn{2}{|c|}{ Mean } & \multirow[t]{2}{*}{ gap } \\
\hline & & F. & T. & F. & T. & \\
\hline \multirow{2}{*}{$\begin{array}{|ll|}\text { 1.Science } & \text { Popular } \\
\text { Education system } & \end{array}$} & (1) Policies and regulations & 3 & 3 & \multirow{2}{*}{3.50} & \multirow{2}{*}{3.00} & \multirow{2}{*}{0.50} \\
\hline & (2)System Guarantee Management System & 4 & 3 & & & \\
\hline \multirow{4}{*}{$\begin{array}{l}\text { 2.Management } \\
\text { responsibility }\end{array}$} & (1) Planning commitment policy & 4 & 2 & \multirow{4}{*}{4.00} & \multirow{4}{*}{2.00} & \multirow{4}{*}{2.00} \\
\hline & (2) System Management & 4 & 2 & & & \\
\hline & (3) Responsibility and authority & 4 & 2 & & & \\
\hline & (4) communication & 4 & 2 & & & \\
\hline \multirow[t]{4}{*}{ 3.Resource Management } & (1) Resource supply & 4 & 3 & \multirow{4}{*}{3.75} & \multirow{4}{*}{3.25} & \multirow{4}{*}{0.50} \\
\hline & (2) Human resources & 4 & 3 & & & \\
\hline & (3) Infrastructure & 4 & 3 & & & \\
\hline & (4) working environment & 3 & 4 & & & \\
\hline \multirow[t]{4}{*}{ 4.service implementation } & (1) Service Planning & 4 & 4 & \multirow{4}{*}{3.00} & \multirow{4}{*}{3.75} & \multirow{4}{*}{-0.75} \\
\hline & (2) design process & 3 & 4 & & & \\
\hline & (3) Service Operation & 3 & 4 & & & \\
\hline & (4) Measuring and monitoring instrument control & 2 & 3 & & & \\
\hline \multirow{4}{*}{$\begin{array}{ll}\text { 5.Measurement, } & \text { Analysis } \\
\text { and Improvement }\end{array}$} & (1) Measurement and monitoring & 2 & 3 & \multirow{4}{*}{2.00} & \multirow{4}{*}{3.00} & \multirow{4}{*}{-1.00} \\
\hline & (2) meet service control & 2 & 3 & & & \\
\hline & (3) Data analysis & 2 & 3 & & & \\
\hline & (4) improve & 2 & 3 & & & \\
\hline Mean value & & & & 3.25 & 3.00 & 0.25 \\
\hline Maturity Grade & & & & $3-4$ & 3 & \\
\hline
\end{tabular}

\section{FINDINGS AND SUGGESTIONS}

The research findings on the maturity level of robots science popular education between Fujian-Taiwan are described as follows, based on which recommendations are made for the consideration of relevant government departments, academia and industry.

\section{A. Research Findings}

1) The science popular education system: The science popular policy is hierarchical in China. At the top level, it is the top-level policy promulgated by the CPC Central Committee, the State Council, and the National People's Congress; the Ministry of Science and Technology and the China Association for Science and Technology jointly establish or independently formulate ministries and commission's policies; and local policies formulated by provinces and cities. 2013 The Ministry of Education issued a file to formally incorporate robots quality education into one of the eight major sports leagues in the country. Robots Education has been part of the National Sports Federation since 2015. Including education courses, this is a milestone in robots education. The policy and legal system of Fujian's robots science education system is affiliated to the China Association of Science and Technology. Fujian's science education is developed and managed by the Fujian Provincial Science and Technology Association. It has a formal program for implementing laws and regulations and is under strict supervision. 


\section{Radar Chart of Robot popular $\epsilon$ maturerity \\ 4}

D5:Measurement, Analysis, and Improvement

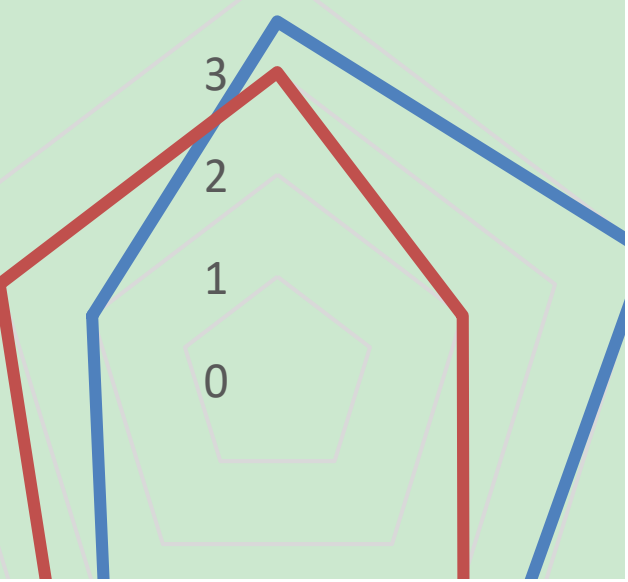

Fig. 1. Radar chart of robots science popular education maturity.

In Taiwan, the first Taiwan High School Robots Society was established in 1997. In Taipei City in 2002, the Taipei Municipal Government began the Taipei Intercity Cup Robots Trials. In 2005, the Executive Yuan Industrial Technology Strategy Conference considered the intelligent robots industry as one of the important development directions. Three stages of development and application strategies for the robots industry are identified, and it is pointed out that tertiary institutions actively invest in robots integration programs to cultivate relevant talents. In the primary and secondary school robots education, from the nine-year consistent syllabus, the 1999 new high school curriculum, to the 2012 state-education curriculum, we can see Taiwan's emphasis on student robots science education. In addition, 107 classes have been determined to adjust information technology and life science and technology into the field of science and technology. Therefore, it can be said that the policies and regulations of robot science popular education between Fujian and Taiwan are the same, however, system guarantee management system of Fujian is better than Taiwan.

2) Management responsibilities: The "People's Republic of China Science and Technology Popularization Law" clearly stipulates that the SCP is the main force of popular science work, and it is responsible for the organization and implementation of science popularization work. In the process of implementing popular science education in China, the main agency responsible for this is the "China Association of Science and Technology." The Chinese Science and Technology Association have set up a science and technology popularization department and are in charge of science and technology work in the science and technology association system. The China Association for
Science and Technology affiliated with 167 national societies, under the Popular Science Working Committee, and the Association for Science and Technology has formed the most complete popular science organization from the central to local systems. Since 2015, robots education has been attributed to the National League of Eight sports league. Taiwan's robots education special management unit is affiliated with the Ministry of Education, but no dedicated unit has yet been established. Under the unified management of the Ministry of Education, the "informal social education" quality resources are actually effectively incorporated into the "regular school education" management service system, so that educational resources can be fully and effectively used. Therefore, it can be said that the management responsibility of robot science popular education of Fujian is better than Taiwan.

\section{3) Resource management}

a) Supply of resources: China's science popularization funds are mainly funded by government funds, and all sectors of society, including the scientific and technological community, media publishing, urban communities, and enterprises, are actively involved in popular science work. In terms of fund utilization, the National Statistical Report on Popular Science in 2006 pointed out that in 2006, China's national science popularization funds from the government's special science programs, department selfraising, and social sponsorship amounted to RMB 4.683 billion, which was the highest in the country's gross production. $1.42 \%$ (Jin, 2008), of which financial allocations from all levels of government reached RMB 3,250 million, which accounted for $69.4 \%$ of the total investment, and the national average public spending activity was RMB 1.18. It can be seen that the Chinese 
government has invested a large amount of funds to support the operation of popular science work, and it has also made its influence and relevant research results promoted to accumulate at an alarming rate. However, in the allocation of popular science resources, there are problems of uneven distribution of urban and rural areas. 9 At present, the mainland government has used a lot of popular science funds to build a large number of popular science venues, popular science multimedia equipment, science resource banks, and database. Compared with the mainland, the overall size of Taiwan's science subsidies and support funds is not large, but the use of subsidy funds in Taiwan's popular science is relatively accurate, with more emphasis on efficiency, reflecting the characteristics of doing more important things with a small amount of funds.

b) Human resources: The existing teachers in Fujian provide collaborative teaching for information technology teachers, general technical teachers, and physics teachers. There are teacher training and on-the-job training in teacher education colleges. Taiwan has not established a method for the cultivation of teachers. The existing teachers hold ${ }^{7}$ for life science teachers or information teachers. Therefore, it can be said that the human resource of robot science popular education of Fujian is better than Taiwan.

c) Infrastructure: Fujian Province has a total of 192 provincial science education bases and 45 national science education bases. However, it is unevenly distributed in the region. Most of them are 40 in Fuzhou, 34 in Xiamen, and only 9 to 12 in Putian, Ningde and Cangzhou. Fuzhou Science and Technology Association has supported 45 science education base platforms, including 8 state-level science education bases, 36 provincial science education bases, and 33 municipal science education bases. According to preliminary statistics, Fuzhou's science education bases at all levels receive over 300,000 students each year for free, and provide 100,000 students with extracurricular practice places each year. In China, Hong Kong, and Taiwan, robots education is an important supplement to basic education. In the early 21 st century, robots education has also entered classrooms.

\section{4) Service realization}

- Planning of service realization: In terms of robots teaching objectives and teaching material content, China is set by the provinces, but it is still to be formulated in Taiwan.

- Design-related process: Robots education students' learning approaches are mainly based on schoolbased curriculum, community or camp teams, and off-campus folk talent classes in Taiwan. However, in Chinese schools, the provinces and cities set their own standards (compulsory, elective, school-based curriculum), and there are children's palaces and minor science stations outside the school.

- Service Operation: Regarding the promotion and advocacy of robots' education, the competition model or interest group model still occupies an absolute dominant position. The robots competitions in Taiwan are mainly inter-provincial schools, FLL (FIRST LEGO League) Robots World Championships, and World Robots Olympiad Competition WRO. The China Youth and Robots Competition, formerly known as the "National Youth Computer Robots Competition," were held in 2001. The competition's projects have been increasing year by year. Take the 2008 eighth competition as an example, the main projects include: (1) China Youth Robots Design Achievements Exhibition And evaluation, (2) intelligent robots competition, (3) 2VS2 juvenile robots soccer competition, (4) FLL robots world championship China competition, (5) FVC robots engineering challenge China competition, (6) impromptu robots battle Wait for six. On the whole, the teaching practice and promotion of robots are still in the initial stage of trial and error. Although a certain scale has been formed, there is still considerable room for improvement in the accumulation of relevant experience and curriculum construction. It also awaits the guidance of related policies.

5) Measure, analyze and improve: There is currently no rigid standard for evaluating the effectiveness of science popular between Fujian and Taiwan. The mainland is gradually establishing procedures and systems for evaluating the effects. After the reform and opening up, especially since entering the 21 st century, the mainland is trying to make a macroscopic and extensive assessment of popular science education for the needs of taxpayers, career development, and scientific management, but it is not strictly defined scientific education effectiveness evaluation. Since Taiwan's popular science education is under the unified management of the education department, the effectiveness assessment is also inseparable from the school's formal education activities (syllabus, teaching plan and curriculum setting, etc.), and it needs to be evaluated separately. However, for the task of science popular education for the whole society, Taiwan's philosophy of efficiency evaluation of popular science activities is relatively scientific and fair. They adhere to the principle of giving priority to social commonweal goals and interpret it in order to prevent them from taking advantage of the public's name in the name of public welfare and various superficial short-sighted values. It is necessary to comprehensively balance the opinions of the audience (including families and schools), media, funders (including government, i.e., public finances), practitioners, and noninterested industry.

6) Difference analysis: Chinese robots popular science activities and competitions are diverse, and they have many similarities with popular science activities in Taiwan, such as the FLL competition and robots competition. China has paid more and more attention to the implementation of robots science education. The formulation of laws and regulations and the investment of funds have played a key 
role in the success or failure of the implementation of robots science education. However, in the implementation, there are still gaps between urban and rural areas and inequality of resources. In addition, the human resources of robots cross strait are in an insufficient period, teachers or technical instructors are lack of uniform standard training and management measures. It is imperative to upgrade the professional quality and ability of technical instructors and establish a standardized robots science education system. China is rich in resources related to science popular education. Not only does it have a large number of popular science bases, but also many science popular education platforms. It is suggested that Taiwan teachers of life science and technology can make good use of it as a supplement to teaching content.

\section{B. Suggestions}

- Set up a dedicated organization to promote robots education: Taiwan is currently under the responsibility of the Ministry of Education, but there is no dedicated agency, and it is advisable to set up an implementation unit to provide robots promotion and supervision.

- Robots education should be included in the formal curriculum system: Robots education can't rely solely on competition or interest groups, which may never be limited to a small number of students in a few schools. Therefore, it must be included in the formal curriculum system, and the same implementation as other disciplines can achieve the effect of popularization.

- Formulate a curriculum standard system: Including curriculum syllabus, course content, teaching aids, hours, etc. Course syllabus and curriculum content can be collaboratively formulated by professional teachers. Educational robots teaching aids can encourage research and development of robots related companies, as long as the function is only to satisfy teaching demand, so the price must be civilian to achieve the purpose of popularizing robots education.

- Develop professional competence standards for robots teachers and strengthen teacher training to make up for the shortage of teachers: The primary education department should combine the strength of universities and the power of enterprises to provide targeted robots teacher training and provide effective teacher assurance for robots courses.

- Develop a robots education evaluation mechanism, and through standard measurement and analysis, we can continuously improve the maturity of robots education.

\section{CONCLUSION}

The article applied the ISO9004 international standard as a self-evaluation standard for robot science education. It would be through the surveys of experts and scholars across the Taiwan Strait. This paper analyzed and compared the maturation degree and differences of the robot science education system between Taiwan and Fujian. The results of the study found that the overall maturity of five evaluations of robotics science education in Fujian fell between a formal stable system plan (3 points) and a focus on continuous improvement (4 points); Taiwan's overall maturity fell on a formal stable system program (3 points), indicating that there are still rooms for improvement in science education across the Taiwan Strait. Due to the core idea of robotics education is innovative thinking and scientific quality, which coincides with the soul and purpose of the national science and technology innovation strategy. The whole process of robot education can enhance the many innate advantages of innovative talents and their ability to solve problems, and this is precisely the talent that the country actively cultivates. Therefore, the promotion of popular science education needs to be celebrated by the relevant government departments, schools, and private companies, and strives to cultivate young people with innovative ideas and scientific literacy.

\section{ACKNOWLEDGMENT}

It should express the deepest gratitude to "Fujian and Taiwan Industrial Collaboration and Management Innovation Research Center" and Fujian Education Science "13th Fiveyear Plan" 2016 Cross-Straits Occupational Education Research Subject with serial number FJJKHX16-062 and name of "Maturity Evaluation of the Quality of Robots Science Popular Education between Fujian and Taiwan".

\section{REFERENCES}

[1] ISO/TC176/SC2 (2000), International Standards for Maturity: Quality Management Systems - Guidelines for Performance Improvements. Geneva: ISO.

[2] Liu Li, Chang Jing, China's science popularization policy and popular science policy culture. Journal of Hechi University Vol.30 No.4, 2010, P.2.

[3] Chen Yijing, Chen Jicheng. The Status and Development of Robots Education in Fujian and Taiwan. Secondary Education Vol. 66 No. 3, 2015, p. 52-53.

[4] Han Zhaokuan, Science and Technology Museums on Both Sides of the Strait. Shanghai Science and Technology, Vol. 2 No. 3 (Total Issue 5), 2010, p.8.

[5] Zheng Zhenhua, Status Quo of Rural Youth Science Education in Fujian Province. No.4 of 2013 (total 293) P.61.

[6] Zhong Baichang and Zhang Lu. Investigation and Analysis of the Status Quo of Robots Education in Primary and Secondary Schools in China, School of Education Science, Nanjing Normal University, China Electrification Education, 2015, July, Issue 342, P.102. 